\title{
Teaching Linear Algebra
}

\author{
Sepideh Stewart, Avi Berman, Christine Andrews-Larson \\ and Michelle Zandieh
}

In this discussion group, the members of the leadership team gave a brief overview of their research, and posed the following set of research questions for discussion:

(a) How can applications of Linear Algebra be used as motivation for studying the topic?

(b) What are the advantages of proving results in Linear Algebra in different ways?

(c) In what ways can a linear algebra course be adapted to meet the needs of students from other disciplines, such as engineering, physics, and computer science?

(d) How can challenging problems be used in teaching Linear Algebra?

(e) In what way should technology be used in teaching Linear Algebra?

(f) What is the role of visualization in learning Linear Algebra?

(g) In what order (picture, symbols, definitions and theorems) should we teach Linear Algebra concepts?

(h) How can we educate the students to appreciate the importance of deep understanding of the Linear Algebra concepts?

Members of the leadership team provided materials for at least 3-4 groups building on themes and resources from their own work which provided the basis for more discussions. Over the two sessions the groups worked on various tasks. These tasks ranged from drawing concept maps of some major linear algebra concepts, to activities that pressed participants to coordinate geometric and algebraic interpretations of solutions to systems of linear equations, to challenging linear algebra tasks.

In the context of these activities, participants offered insights and perspectives from their experiences related to the teaching and learning of linear algebra from their country and institution.

\footnotetext{
S. Stewart $(\square)$

University of Oklahoma, Norman Campus, Norman, USA

e-mail: sstewart@math.ou.edu

(C) The Author(s) 2017

G. Kaiser (ed.), Proceedings of the 13th International Congress on Mathematical

Education, ICME-13 Monographs, DOI 10.1007/978-3-319-62597-3_107
} 


\section{Moving Forward}

After the conference we accepted an invite from ICME-13 and proposed an edited manuscript. The work will appear in:

Stewart, S., Andrews-Larson, C., Berman, A., \& Zandieh, M. Challenges and strategies in teaching linear algebra. Berlin: Springer.

Open Access Except where otherwise noted, this chapter is licensed under a Creative Commons Attribution 4.0 International License. To view a copy of this license, visit http://creativecommons. org/licenses/by/4.0/.

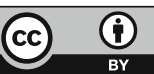

